\title{
ACACIA GLOBosa E ACACIA LIMAE, DUAS NOVAS ESPÉCIES DE LEGUMINOSAE-MimosoIDEAE PARA O BRASIL ${ }^{1}$
}

\author{
Ana Luiza Du Bocage \& Silvia Teresinha Sfoggia Miotto $^{3}$
}

\section{Resumo}

(Acacia globosa e Acacia limae, duas novas espécies de Leguminosae-Mimosoideae para o Brasil) Acacia globosa e A. limae são descritas e ilustradas. Acacia globosa é semelhante à A. riparia, da qual difere pelo número de pares de folíolos 5-7, pelo pecíolo, ráquis foliar e foliólulos seríceos. Acacia limae também é próxima de A. riparia, diferindo pelas glândulas do pecíolo estipitadas e clavadas. Acacia globosa é endêmica no estado da Bahia e Acacia limae é encontrada nos estados da Bahia, Pernambuco e Minas Gerais.

Palavras-chave: Acacia, Leguminosae, Mimosoideae, caatinga, Brasil.

\section{Abstract}

(Acacia globosa and Acacia limae, two new species of Leguminosae-Mimosoideae in Brazil) Acacia globosa and A. limae are described and illustrated. Acacia globosa is similar to A. riparia, from which it differs in the number of pairs of pinnae 5-7, by the petiole, sericeous rachis and leaflets. Acacia limae is also close to $A$. riparia, differing in the stipitate and clavate petiole glands. The first species is endemic in the state of Bahia, and the second is found in the states of Bahia, Pernambuco and Minas Gerais.

Key-words: Acacia, Leguminosae, Mimosoideae, caatinga, Brazil.

Acacia é o segundo maior gênero de Leguminosae, com cerca de 1.350 espécies e com distribuição cosmopolita (Maslin et al. 2003). No Brasil, há aproximadamente 44 espécies, as quais ocorrem desde a Região Norte, até a Região Sul do país (RicoArce 2003). As espécies deste gênero vivem em ambientes muito diversos, desde florestas tropicais perenifólias, às regiões mais áridas do mundo (Rico-Arce 2003). No semi-árido brasileiro as 16 espécies ocorrem, preferencialmente, em caatinga arbórea, caatinga arbustiva e mata de cipó (Du Bocage 2005). O gênero Acacia está dividido, segundo Vassal (1972) em três subgêneros: Acacia subg. Acacia, A. subg. Aculeiferum e A. subg. Phyllodinea. As espécies aqui descritas pertencem ao subg. Aculeiferum, por possuírem acúleos.
Acacia globosa A. Bocage \& Miotto, sp. nov. Tipo: BRASIL. BAHIA: Palmeiras, 3.III.2003, fl., A. Bocage, C. N. Gonçalves \& C. F. Azevedo-Gonçalves 872 (holótipo ICN, isótipo IPA). $\quad$ Fig. 1

Acacia globosa petiolo instructo glandula unica; glandula sessili et globosa, $1.0 \mathrm{~mm}$ longa et foliolulis sericeis supra et infra distingueda. Haec species A. riparia Kunth affinis sed 5-7 foliolulis, petiolo, rhachidi filiacea et foliolulis sericies differt. Etiam affinis A. limae amplitudine et forma leguminum et numero foliolulorum.

Arbustos 2 a 3 m alt. Ramos levemente angulosos, com acúleos recurvos e esparsos, $1 \mathrm{~mm}$ compr. Estípulas não vistas. Folhas 5-7 pares de folíolos; pecíolo canaliculado, seríceo, 1-1,7 cm compr., glândula séssil, globosa, 1 $\mathrm{mm}$ compr., no meio do pecíolo; ráquis foliar canaliculada, serícea, $6-6,5 \mathrm{~cm}$ compr., geralmente aculeada, com glândulas iguais as

\footnotetext{
Artigo recebido em 09/2005. Aceito para publicação em 01/2006.

${ }^{1}$ Parte da tese de Doutorado da primeira autora apresentada ao Curso de Pós-Graduação em Botânica, da Universidade Federal do Rio Grande do Sul. Apoio financeiro: CNPq.

${ }^{2}$ Empresa Pernambucana de Pesquisa Agropecuária - IPA, Av. Gal. San Martin, 1371, Bongi, 50761-000, Recife, Pernambuco, Brasil. dubocage@terra.com.br

${ }^{3}$ Departamento de Botânica - Universidade Federal do Rio Grande do Sul, Av. Bento Gonçalves, 9500, bloco IV, prédio 43433, 91501-970, Porto Alegre, Rio Grande do Sul, Brasil.
} 
do pecíolo, porém menores, entre os dois últimos pares de folíolos; folíolos com 17-25 pares de foliólulos, sésseis a curtamente peciolulados, 5-6 × 1,5-2 mm, oblongos, base levemente oblíqua, ápice obtuso, membranáceos, seríceos em ambas as faces, margem ciliada, nervura principal central. Panículas axilares e terminais, apresentando fascículos de 2 a 4 glomérulos globosos ao longo dos eixos e/ou glomérulos axilares, glomérulos 1,7-2,2 mm diâm.; brácteas caducas, 1,5 mm compr., espatuladas, velutinas, no meio do pedúnculo; bractéolas semelhantes, menores que as brácteas; pedúnculo 1,2-2 cm compr., seríceo; flores curtamente pediceladas; cálice tubuloso, 2,5-3 mm compr., glabro na base e puberulento no ápice, lacínias $0,5 \mathrm{~mm}$ compr.; corola tubulosa, 5-6 mm compr., glabra na base e puberulenta no ápice, lacínias $0,5 \mathrm{~mm}$ compr.; estames creme; ovário glabro, 1,5 mm compr., estípite $1 \mathrm{~mm}$ compr. Legumes 11,5-16 ×2,5$3 \mathrm{~cm}$, elípticos, base atenuada, ápice apiculado a agudo, glabros, castanho-escuros, margem saliente; sementes $1-1,2 \times 0,6-0,7 \mathrm{~cm}$, elípticas, marrom-escuras.

Parátipos: BRASIL. BAHIA: Abaíra, na estrada para Catolés, 25.XII.1988, fl., R. $M$. Harley et al. 27741 (CEPEC); id., arredores de Catolés, na estrada para Guarda Mor, 27.XII.1988, fl., R. M. Harley et al. 27823 (CEPEC); Catolés, 1317'00'S 41 51'00'W, 20.XII.1991, fl., R. M. Harley et al. 50178 (HUEFS); id., 31.X.1996, fl., L. P. Queiroz \& M. M. Silva 3846 (HRB); id., Catolés-Água Limpa, 18.IX.1999, fl., A. S. Conceição et al. 366 (HUEFS, ICN); estr. Bom Jesus da LapaIgapora, km 33, 2.VII.1983, fl. fr., L. Coradin et al. 6336 (CEPEC); Livramento do Brumado, na rodovia para vila de Rio de Contas, 13³9'00'S 4150'00'”W, 23.III.1977, fl. fr., R. M. Harley 19846 (CEPEC, IPA); Cachoeira do Brumado, 2,5 km na estrada de Livramento do Brumado para Rio de Contas, 28.III.1991, fl. fr., G. P. Lewis \& S. M. M. de Andrade 1926 (CEPEC); Dom Basílio, Fazendinha, 28.XII.1989, fl. fr., A. $M$.
Carvalho et al. 2694 (CEPEC); Itaberaba, 22.III.2000, fl., P. Unaldo 67 (HUEFS); Malhada de Pedras, estrada que liga a BR 030 a Malhada de Pedras, 28.III.1984, fr., J. E. M. Brazão 288 (RB); Mucugê, na estrada AbaíraMucugê, 14.II.1992, fl. fr., L. P. Queiroz 2623 (CEPEC, HUEFS); Palmeiras, $36 \mathrm{~km}$ da BR 242, 17.XI.1983, fl., G. C. P. Pinto et al. 448 (CEPEC, HRB); id., 3.X.2003, fl., A. Bocage et al. 870 (ICN); Piatã, estrada Catolés-Ouro Verde, 28.VIII.1992, fl., W. Ganev 983 (CEPEC); id., estrada Catolés/Piatã, 1314'46" S 41\%45'26"W, 9.XI.1996, fl., W, H. P. Bautista \& D. J. N. Hind 4179 (ALCB, CEPEC, HRB); id., margem da estrada, antes de Pindobal, 19.II.2000, fl., F. S. Cavalcanti $s / n$ (EAC 29151); Rio de Contas, Pico das Almas, 1332'00"S 41'54'00"'W, 11.XI.1988, fl., R. M. Harley \& B. Stannard 27119 (CEPEC); id., 25.I.1998, fl., L. P. Queiroz et al. 4936 (HUEFS); id., estrada para o povoado de Mato Grosso, 27.II.2001, fl., R. M. Harley \& A. M. Giulietti 54113 (HUEFS); id., estrada Real, s/d, fl., A. M. Giulietti \& R. M. Harley 1602 (HUEFS).

Acacia globosa apresenta muitas semelhanças morfológicas com A. riparia, como porte arbustivo, cor e tamanho dos glomérulos, porém difere no número de pares de folíolos e na pilosidade da ráquis foliar e dos foliólulos.

Bentham (1876) cita A. riparia para os estados do Rio de Janeiro e São Paulo. Segundo Silva (1990) esta espécie ocorre na América do Sul, no Perú e Brasil (Amazonas). $\mathrm{Na}$ região do semi-árido ocorre nos estados do Piauí, Ceará, Bahia e Minas Gerais (Du Bocage 2005). Já, A. globosa é endêmica da Bahia, preferencialmente no Complexo da Chapada Diamantina, em caatinga arbustiva e cerrado. Floresce de janeiro a março e de agosto a dezembro e frutifica de fevereiro a março.

O epíteto específico refere-se à forma globosa da glândula peciolar. 

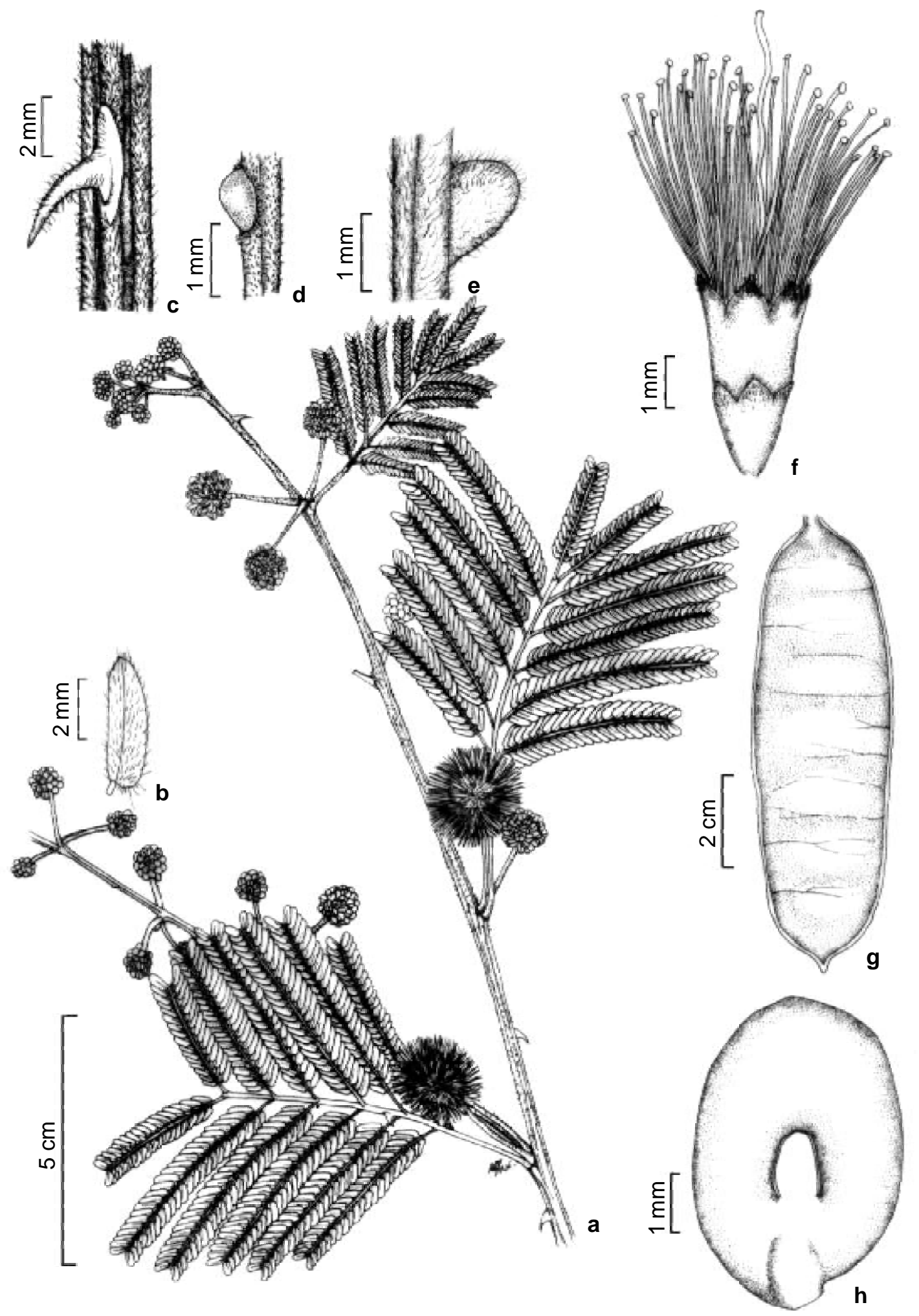

Figura 1 - Acacia globosa A. Bocage \& Miotto. a. Ramo com inflorescências; b. foliólulo; c. acúleo; d. glândula da ráquis foliar; e. glândula do pecíolo; f. flor; g. legume; h. semente. (Bocage 872). 
Acacia limae A. Bocage \& Miotto, sp. nov. Tipo: BRASIL. BAHIA: Abaíra, após Brejo de Cima, 5.X.2003, fl., A. Bocage, C. N. Gonçalves \& C. F. Azevedo-Gonçalves 895 (holótipo ICN, isótipo IPA).

Fig. 2

$A b$ Acacia limae petiolo duabus glandulis stipitatis clavatisque instructo, 1$1.5 \mathrm{~mm}$ longis, foliolulis pubescentibus ad velutinos supra et infra distinguenda. Affinis A. riparia Kunth glandula unica vel duabus, sessilibus, elliptico-globosis et foliolulis glabris differt.

Arbustos 2 a 3 m alt. Ramos com acúleos recurvos e retos, $4 \mathrm{~mm}$ compr. Estípulas não vistas. Folhas 6-9 pares de folíolos; pecíolo canaliculado, velutino, 1-2 cm compr., com uma a duas glândulas estipitadas, clavadas, 1-1,5 mm compr.; ráquis foliar canaliculada, velutina, 5-8 cm compr., aculeada, com glândulas iguais as do pecíolo, $1 \mathrm{~mm}$ compr., entre os dois últimos pares de folíolos; folíolos com 17-26 pares de foliólulos, curtamente peciolulados, $0,7-1 \times 0,2 \mathrm{~cm}$ compr., lineares a ligeiramente falcados, base oblíqua, ápice arredondado, membranáceos, pubescentes a velutinos em ambas as faces, margem ciliada, nervura principal pouco excêntrica. Panículas axilares e terminais, apresentando fascículos de 2 a 4 glomérulos globosos, 1,4-3 cm diâm., ao longo dos eixos; brácteas caducas, $2 \mathrm{~mm}$ compr., espatuladas, velutinas, no terço superior do pedúnculo; bractéolas semelhantes, menores que as brácteas; pedúnculo 1-2 cm compr., velutino; flores sésseis; cálice tubuloso, 3-3,5 $\mathrm{mm}$ compr., glabro na base e pubescente no ápice das lacínias, lacínias desiguais, 0,5 mm compr.; corola tubulosa, $4 \mathrm{~mm}$ compr., glabra com tufos de tricomas no ápice, lacínias $1 \mathrm{~mm}$ compr.; estames creme; ovário glabro, 1,5-2 $\mathrm{mm}$ compr., estípite $1 \mathrm{~mm}$ compr. Legumes 11-13 × 3-3,5 cm, elípticos, base atenuada, ápice apiculado, apículo 0,5-0,7 cm compr., glabros, marrom-arroxeados, margem saliente; sementes $0,9-1,1 \times 0,7-0,8 \mathrm{~cm}$, elípticas, marrom-escuras.

Parátipos: BRASIL. BAHIA: Abaíra, João Correia ao redor da cidade, 5.X.2003, fl., A.
Bocage et al. 896 (ICN); id., 5.X.2003, fl., A. Bocage et al. 899 (ICN); Bom Jesus da Lapa, 2.VII.1983, 13²6'00"S 04³1'00'"W, fl. fr., $L$. Coradin et al. 6336 (CEPEC); Caetité, Barragem de Captação, 28.XI.1992, fl. fr., $M$. L. Guedes et al. 2699 (ALCB); Carinhanha, para Serra do Ramalho, 15.IV.2001, fr., J. G. Jardim et al. 3515 (CEPEC); Dom Basílio, 9.II.1990, fl., A. Miranda \& F. Esteves 146 (RB); id., Fazendinha, 28.XII.1989, A. M. Carvalho et al. 2694, fl. fr., (CEPEC); Encruzilhada, 22.VII.1980, fr., J. E. M. Brazão 79 (HRB); Guanambi/Caetité, 28.IV.1995, fl., M. Andrade \& B. Cavada s/n (EAC 22813); Livramento do Brumado, 28.III.1991, fl. fr., $G$. P. Lewis \& M. M. de Andrade 1926 (HUEFS); Malhada de Pedras, 28.III.1984, fr., J. E. M. Brazão 288 (HRB, RB); Morro do Chapéu, Lages, 7.III.2003, fl., L. P. Queiroz et al. 7633 (HUEFS); Mucugê, 5.X.2003, fl., A. Bocage et al. 897 (ICN); id., 5.X.2003, fl., A. Bocage et al. 898 (ICN); Palmeiras, $1 \mathrm{~km}$ de Tejuca, 5.X.2003, fl., A. Bocage et al. 892 (ICN); Paramirim, estrada de ParamirimCaetité, 13³4'38's 42¹6'53"'W, 19.IV.2001, fl. fr., T. R. S. Silva et al. 88 (HUEFS); Poções, $\mathrm{km} 2$ a 4 da estrada que liga Poções ao povoado de Bom Jesus da Serra, 5.III.1978, fl., S. A. Mori et al. 9486 (CEPEC); entre Segredo e Mulungu, 25.IX.1965, fl., A. P. Duarte \& E. Pereira 10094 (RB). MINAS GERAIS: Jaíba, estrada da Profaz, 27.XI.1984, fl., Teixeira \& Carvalho $s / n$ (BHCB 7342); Matias Cardoso, 27.II.1984, fl., Teixeira s/n (RB 363788). PERNAMBUCO: Brejo da Madre de Deus, Mata do Malhada, 28.IV.2000, fl., A. G. da Silva \& L. M. Nascimento 290 (RB); Pesqueira, Serra do Ororobá, fazenda São Francisco, 16.V.1996, fl., M. Correia 231 (UFP).

Acacia limae é próxima de A. riparia, pelo porte arbustivo e pelo tipo de inflorescência, diferindo pelas glândulas estipitadas e clavadas e pelos foliólulos pubescentes a velutinos em ambas as faces. É também afim de A. tucumanensis Griseb., porém, esta apresenta foliólulos glabros, 


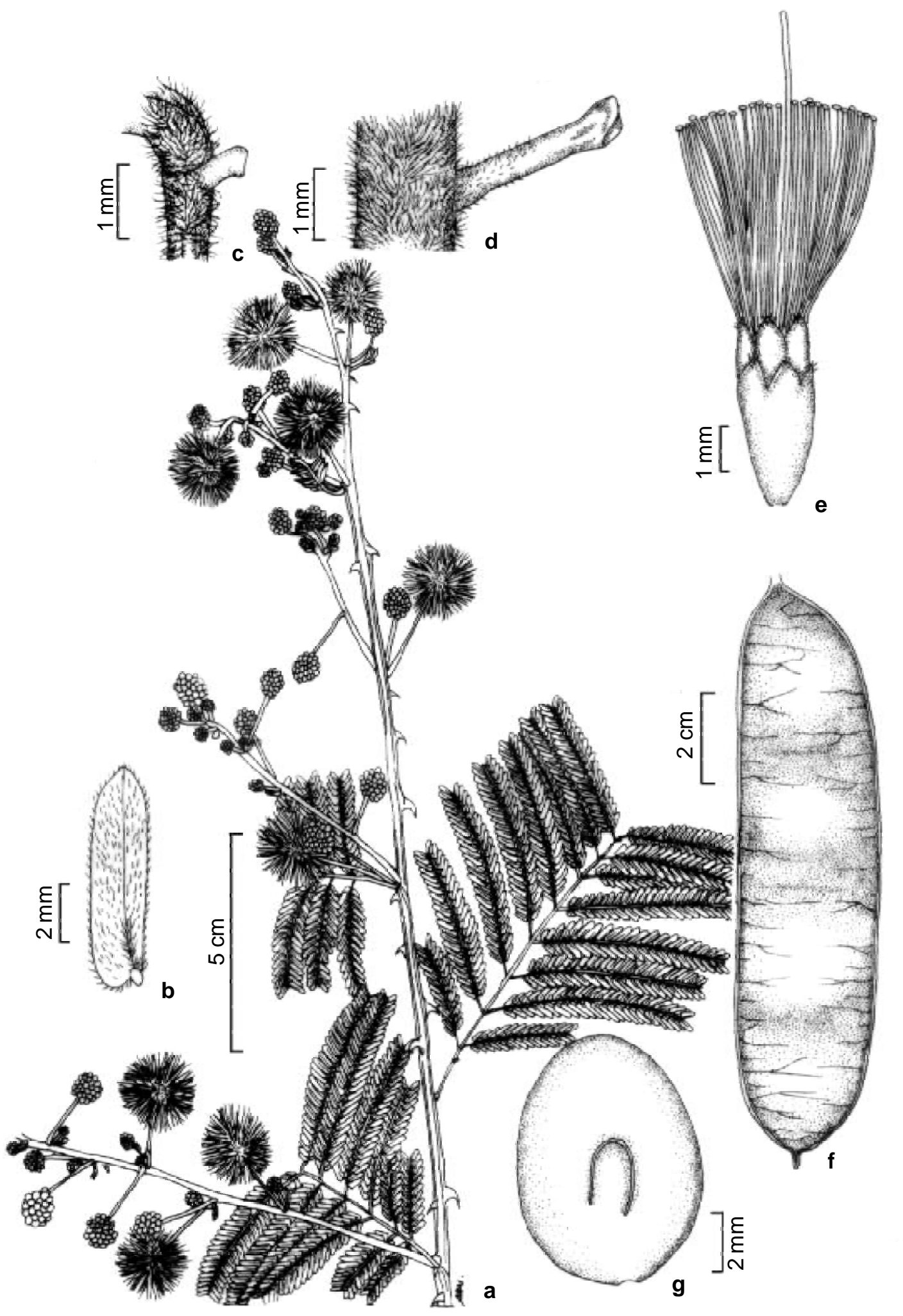

Figura 2 - Acacia limae A. Bocage \& Miotto. a Ramo com inflorescências; b. foliólulo; c. glândula da ráquis foliar; d. glândula do pecíolo; e. flor; f. legume; g. semente. (Bocage 895). 
ocorrendo somente no Brasil austral, Argentina (províncias de Tucumán, Salta, Jujuy e Misiones) e Paraguai.

As duas espécies aqui descritas são próximas, porém diferem entre si pela forma das glândulas do pecíolo e da ráquis foliar.

Acacia limae ocorre nos estados de Pernambuco, Bahia e norte de Minas Gerais, em caatinga arbustiva, cerrado e floresta estacional. Floresce e frutifica ao longo de todo o ano. $\mathrm{O}$ epíteto específico é uma homenagem ao Dr. Dárdano de Andrade-Lima, grande conhecedor da flora do semi-árido brasileiro, em especial, da família Leguminosae.

\section{Agradecimentos}

Agradecemos ao Dr. Tarciso Filgueiras pelas diagnoses latinas. À desenhista Anelise Scherer pelas ilustrações. Ao CNPq pela concessão de bolsa de doutorado à primeira autora e de Produtividade Científica à segunda autora.

\section{REFERÊNCIAS BIBLIOGRÁFICAS}

Bentham, G. 1876. Leguminosae Mimosoideae. In: C. F. P. Martius (ed.) Flora brasiliensis. Monachii, Lipsiae, Fridr. Fleischer. 15: 392406.
Du Bocage, A. L. 2005. O gênero Acacia Mill. (Leguminosae-Mimosoideae) no semi-árido brasileiro. Tese de Doutorado, Universidade Federal do Rio Grande do Sul, 131p.

Maslin, B. R.; Miller, J. T. \& Seigler, D. S. 2003. Overview of the generic status of Acacia (Leguminosae:Mimosoideae). Australian Systematic Botany 16: 1-18.

Rico-Arce, L. 2003. Geographical patterns in neotropical Acacia (Leguminosae: Mimosoideae). Australian Systematics Botany 16: 41-48.

Silva, A. S. L. 1990. Contribuição ao estudo sistemático das espécies do gênero Acacia Mill. (Leguminosae: Mimosoideae) ocorrentes na Amazônia brasileira. Boletim do Museu Paraense Emílio Goeldi, ser. Bot. 6:154-226.

Vassal, J. 1978. Apport des recherches ontogeniques et seminologiques a l'étude morphologique, taxonomique et phylogenique du genre Acacia. Bulletin de la societè $\mathrm{d}$ histoire naturelle de Toulouse 108: 105-247. 
